Subscriber access provided by Lib4RI - Library for Eawag, Empa, PSI \& WSL

\title{
Environmental Processes
}

\section{Photochemical production of sulfate and methanesulfonic acid from dissolved organic sulfur}

Rachele Ossola, Julie Tolu, Baptiste Clerc, Paul Ragnar Erickson, Lenny H.E. Winkel, and Kristopher McNeill

Environ. Sci. Technol., Just Accepted Manuscript • DOI: 10.1021/acs.est.9b04721 • Publication Date (Web): 10 Oct 2019

Downloaded from pubs.acs.org on October 15, 2019

\section{Just Accepted}

"Just Accepted" manuscripts have been peer-reviewed and accepted for publication. They are posted online prior to technical editing, formatting for publication and author proofing. The American Chemical Society provides "Just Accepted" as a service to the research community to expedite the dissemination of scientific material as soon as possible after acceptance. "Just Accepted" manuscripts appear in full in PDF format accompanied by an HTML abstract. "Just Accepted" manuscripts have been fully peer reviewed, but should not be considered the official version of record. They are citable by the Digital Object Identifier (DOI®). "Just Accepted" is an optional service offered to authors. Therefore, the "Just Accepted" Web site may not include all articles that will be published in the journal. After a manuscript is technically edited and formatted, it will be removed from the "Just Accepted" Web site and published as an ASAP article. Note that technical editing may introduce minor changes to the manuscript text and/or graphics which could affect content, and all legal disclaimers and ethical guidelines that apply to the journal pertain. ACS cannot be held responsible for errors or consequences arising from the use of information contained in these "Just Accepted" manuscripts.

This document is the accepted manuscript version of the following article:

Ossola, R., Tolu, J., Clerc, B., Erickson, P. R., Winke1, L. H. E., \& MCNei11, K. (2019). Photochemical production of sulfate and methanesulfonic acid from dissolved organic sulfur. Environmental Science and Technology.

https://doi.org/10.1021/acs.est.9b04721 


\section{Photochemical production of sulfate and methanesulfonic acid from dissolved} organic sulfur Rachele Ossolal, Julie Tolu ${ }^{1,2}$, Baptiste Clerc ${ }^{l}$, Paul R. Erickson ${ }^{l}$, Lenny H. E. Winkel ${ }^{1,2}$,

$4 \quad$ Kristopher McNeill ${ }^{1, *}$

\section{Author address}

$6{ }^{1}$ Institute of Biogeochemistry and Pollutant Dynamics (IBP), Department of Environmental

$7 \quad$ System Science, ETH Zürich, 8092 Zürich Switzerland

82 Eawag Swiss Federal Institute of Aquatic Science and Technology, 8600 Dübendorf

$9 \quad$ Switzerland

10 Keywords Dissolved organic sulfur, environmental photochemistry, biogeochemical cycles,

11 sulfate, methanesulfonic acid, methanesulfinic acid, mineralization.

\section{Abstract}

13 Photodegradation processes play an important role in releasing elements tied up in biologically

14 refractory forms in the environment, and are increasingly recognized as important contributors to

15 biogeochemical cycles. While complete photooxidation of dissolved organic carbon (to $\mathrm{CO}_{2}$ ),

16 and dissolved organic phosphorous (to $\mathrm{PO}_{4}{ }^{3-}$ ) has been documented, the analogous

17 photoproduction of sulfate from dissolved organic sulfur (DOS) has not yet been reported.

18 Recent high-resolution mass spectrometry studies showed a selective loss of organic sulfur

19 during photodegradation of dissolved organic matter, which was hypothesized to result in the 20 production of sulfate. Here, we provide evidence of ubiquitous production of sulfate, 21 methanesulfonic acid (MSA) and methanesulfinic acid (MSIA) during photodegradation of 


\section{TOC art}

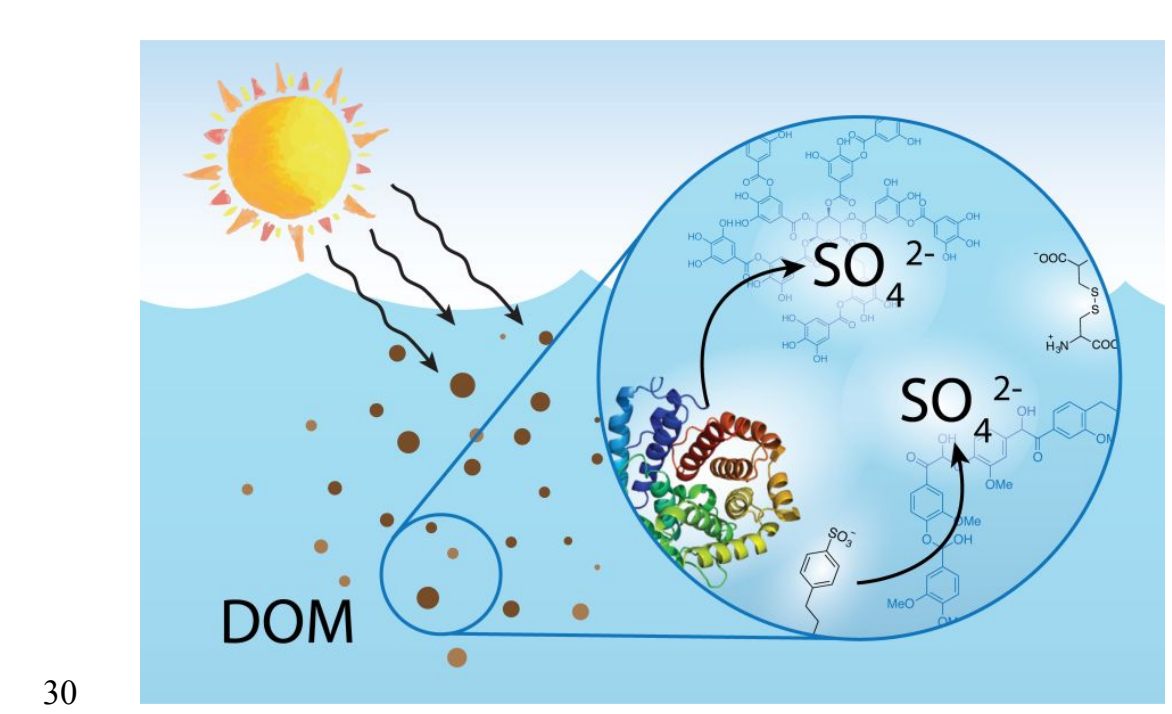

DOM samples from a wide range of natural terrestrial environments. We show that photochemical production of sulfate is generally more efficient than the production of MSA and MSIA, as well as volatile S-containing compounds (i.e., $\mathrm{CS}_{2}$ and COS). We also identify possible molecular precursors for sulfate and MSA, and we demonstrate that a wide range of relevant classes of DOS compounds (in terms of S oxidation state and molecular structure) can liberate sulfate upon photosensitized degradation. This work suggests that photochemistry may play a more significant role in the aquatic and atmospheric fate of DOS than currently believed. 


\section{Introduction}

Photochemical processes convert biologically recalcitrant organic molecules into low molecular weight compounds and inorganic species, enhancing their bioavailability and thus their mobility across environmental compartments. ${ }^{1}$ The attention on the role of photochemistry in the biogeochemical cycles has been increasing over the last years, especially for those environments in which biological processes are inherently slow due to low temperatures, lack of water, or both. ${ }^{2}$ For example, photodegradation of dissolved organic carbon (DOC) was reported to be responsible for $75-90 \%$ of the total carbon turnover in arctic lakes and rivers, ${ }^{3}$ while in dryland systems, incorporation of photochemical processes led to substantial improvements of C-cycling models ${ }^{4}$. In addition, photochemistry is considered an important degradation pathway for terrestrial DOC in coastal areas, with $3-40 \%$ of riverine DOC input expected to be photochemically mineralized within a few years. ${ }^{1,2}$ So far, the organic matter photomineralization studies have focused primarily on carbon, and secondarily on nitrogen and phosphorus (see reference (1)). However, we can anticipate similar processes for other elements that are part of the organic matter pool, such as sulfur.

In this context, the identification and distribution of photodegradation products is the first step to understand and quantify the role of sunlight in the biogeochemical cycles. Photochemical degradation of DOC into $\mathrm{CO}_{2}, \mathrm{CO}$, and a suite of low molecular weight carbonyls and carboxylates has been extensively documented in freshwater and marine environments. 1,5 Similarly, dissolved organic nitrogen (DON) is photochemically degraded to $\mathrm{NH}_{4}^{+}$, primary amines, amino acids and urea, ${ }^{1,6,7}$ while dissolved organic phosphorous (DOP) was shown to release $\mathrm{PO}_{3}^{4-}$ upon photolysis ${ }^{1,8}$. On the other hand, less is known about the photochemical fate of dissolved organic sulfur (DOS). So far, only carbonyl sulfide (COS) and carbon disulfide 
$54\left(\mathrm{CS}_{2}\right)$, have been reported as DOS photoproducts, with the majority of the studies focusing on

the marine environment. ${ }^{1,9}$ Other authors showed the formation of dimethylsulfoxide (DMSO) from the photodegradation dimethylsulfide (DMS), a volatile organosulfur compound produced by marine phytoplankton. ${ }^{1,10}$ To the authors' knowledge, no direct evidence of the photochemical formation of sulfate from DOS has been reported so far, even if it might be anticipated based on the photochemical behavior of DOC, DON and DOP.

There is solid support for the photochemical reactivity of DOS. Studies using high-resolution mass spectrometry (HRMS) showed a high photochemical lability of sulfur-containing organic molecules from saltmarsh, ${ }^{11}$ deep sea, ${ }^{12}$ coastal $\operatorname{arctic}^{13}$ and acid mine drainage ${ }^{14}$. These studies consistently reported faster degradation kinetics of $\mathrm{CHOS}$ formulas compared to $\mathrm{CHO}$ formulas, and observed the conversion of CHOS into $\mathrm{CHO}$, implying photochemical loss of organic sulfur. Based on mass balance considerations, we hypothesized that the loss of sulfur should be associated with the formation of sulfate (photomineralization) and/or other small oxidized Scontaining molecules that might elude HRMS detection. This hypothesis is further supported by the available literature on the photochemistry of DMS, COS and $\mathrm{CS}_{2}{ }^{1,15}$ and has already been put forward by some authors ${ }^{12,14}$. In this work, we provide direct demonstration that non-volatile DOS undergoes facile photochemical conversion to sulfate and other small non-volatile organic compounds, such as methanesulfonic acid $\left(\mathrm{CH}_{3} \mathrm{SO}_{3} \mathrm{H}\right.$, MSA $)$ and methanesulfinic acid $\left(\mathrm{CH}_{3} \mathrm{SO}_{2} \mathrm{H}, \mathrm{MSIA}\right)$, under environmentally relevant conditions. Together with the enzymatic hydrolysis of sulfate esters observed in anoxic lake sediments, ${ }^{16}$ the photochemical degradation of DOS to sulfate represents one of the few known mineralization (i.e., conversion to $\mathrm{SO}_{4}^{2-}$ ) routes of organic S compounds in aquatic systems. 


\section{Materials and methods}

\section{Chemicals and organic matter samples}

The twenty-two DOS model compounds, the actinometry compounds and the standards for the analyses were purchased from commercial vendors (Supplementary Text S1). The eight reference DOM samples were obtained from the International Humic Standard Society (IHSS,

St. Paul, Minnesota), while the ten whole water samples were collected in several sites ranging from Switzerland (Étang de la Gruyère), to North America (Great Dismal Swamp, Lake Bradford, Prairie Pothole peat bogs) and Sweden (Storhultsmossen peat bog). More details on collection and handling of the water samples and isolates can be found in the Supplementary Texts S1 and S2.

\section{Photodegradation experiments}

The photolysis experiments were performed on reference DOM samples and on field-collected natural waters or their solid phase extracts at a concentration of $\approx 20 \mathrm{mg}_{\mathrm{C}} \mathrm{L}^{-1}$ (natural water experiments), or on solutions containing Dismal Swamp as natural sensitizer (DS2014, $\approx 20 \mathrm{mg}_{\mathrm{C}}$ $\left.\mathrm{L}^{-1}\right)$ and the selected DOS model compound $(50 \mu \mathrm{mol} \mathrm{L}-1)$ (model compounds experiments). The natural water experiments were performed at least in triplicates, while the model compounds experiments at least in duplicate. A summary of the initial dissolved organic carbon (DOC) and sulfate concentrations, $\mathrm{pH}$ and $\mathrm{SUVA}_{254}$ values for the nineteen experimental natural water solutions is provided in Table S1. Selected DOS model compounds include thiols (cysteine, glutathione, 3-mercaptopropionic acid, 3-(methylthio)benzoic acid), thioethers (methionine, biotin, thioanisole, 3-mercaptobenzoic acid), thiophenes (2,2'-bithiophene), thioamides (thioacetamide), sulfonic acids (cysteinesulfonic acid, methanesulfonic acid, 1-hexanesulfonic 
acid, 2-(cyclohexylamino)ethanesulfonic acid, taurocholic acid, benzenesulfonic acid, 4toluenesulfonic acid, 1,2-naphthoquinone-4-sulfonic acid, 4-dodecylbenzenesulfonic acid) and organosulfate esters (pregnenolone sulfate, 4-nitrocatechol sulfate). The chemical structures are reported in the Supplementary Materials.

The experimental solutions $(10 \mathrm{~mL})$ were placed in cork-stoppered borosilicate test tubes (Pyrex, $15 \times 85 \mathrm{~mm}$, disposable) and were irradiated for 5 hours inside a photoreactor (Rayonet, Southern New England Ultraviolet Co) equipped with $6 \times$ UVB light bulbs (Southern New England Ultraviolet Co, RPR-3000 A lamps, peak emission at $310 \mathrm{~nm}$ ) and a turntable. During irradiation, a fan was turned on to keep the temperature constant around $30-32{ }^{\circ} \mathrm{C}$. At each hour, an aliquot was withdrawn for quantification of sulfate via ion chromatography (IC). In the model compound experiments, MSA was also quantified via IC. For the quantification of volatile and non-volatile DOS products in the natural water experiments, an aliquot was withdrawn at the beginning and at the end of the irradiation. MSA and MSIA were quantified by HPLC-ICPMS/MS, while volatile compounds were estimated from total S measurements via ICP-MS/MS. Total S was also measured in irradiated gas-purged solutions to assure that only non-volatile compounds were detected.

The light intensity inside the photoreactor was monitored with the chemical actinometer $p$ nitroanisole/pyridine (PNA-py). ${ }^{17}$ A solution containing $20 \mu \mathrm{mol} \mathrm{L}^{-1}$ of PNA and $0.25 \mathrm{mmol} \mathrm{L}^{-1}$ of pyridine in nanopure water was irradiated for 5 hours in the experimental conditions described above. PNA and pyridine were quantified via ultra-high-performance liquid chromatography (UPLC) with UV detection. For the sulfate production experiments from DOM and model compounds, we calculated an integrated irradiance of $65 \pm 4 \mathrm{~J} \mathrm{~s}^{-1} \mathrm{~m}^{-2}(\Delta \lambda=290-400 \mathrm{~nm}$, see also Figure S1), while for experiments investigating volatile compounds, MSA and MSIA 
122 production from natural DOM, the irradiance over the same wavelength range was $46 \pm 5 \mathrm{~J} \mathrm{~s}^{-1} \mathrm{~m}^{-}$

1232 . More details can be found in the Supplementary Text S3.

124 Control experiments. Control experiments were also performed to unambiguously attribute 125 sulfate, MSA or MSIA production to photochemical processes, and to show that sulfate

126 production from DOS is in principle possible under natural sunlight (i.e., at $\lambda>300290 \mathrm{~nm}$ ), and

127 in the presence of low DOC and high salts concentrations (i.e., in conditions typical of marine 128 environments). The detailed description of the control experiments is provided in the 129 Supplementary Text S4.

\section{Chemical analyses}

131 Sulfate and MSA quantification via ion chromatography (IC). Sulfate and MSA were quantified via ion chromatography using either a DX-320 IC instrument (Thermo Scientific, Sunnyvale, CA, USA), or a 940 Professional IC Vario instrument (Metrohm). The DX-320 system was equipped with an EG40 eluent gradient generator, a Dionex Ion Pack AG11-HC RFIC 4 mm column and its guard column, a Dionex AERS $5004 \mathrm{~mm}$ electric suppressor and an electrical conductivity detector. The sample injection volume was $250 \mu \mathrm{L}$, the flow rate was $1.5 \mathrm{~mL} \mathrm{~min}^{-1}$ and the following $\mathrm{KOH}$ gradient was used: $0-11 \mathrm{~min}, 1 \mathrm{mmol} \mathrm{L}^{-1}$; $11-37 \mathrm{~min}, 1 \mathrm{mmol} \mathrm{L}^{-1}$ to

$13840 \mathrm{mmol} \mathrm{L}^{-1} ; 37$ to $38 \mathrm{~min}, 40 \mathrm{mmol} \mathrm{L}^{-1}$ to $1 \mathrm{mmol} \mathrm{L}^{-1} ; 38$ to $41 \mathrm{~min}, 1 \mathrm{mmol} \mathrm{L}^{-1}$. In these conditions, sulfate was eluted at $24.0 \mathrm{~min}$ and had an average detection limit of $0.15 \mu \mathrm{mol} \mathrm{L}-1$.

140 The Metrohm system was equipped with a Metrosep A Supp 5-250/4.0 column thermostated at $14130^{\circ} \mathrm{C}$, a conductivity detector, a chemical suppressor, and was run in isocratic mode. The mobile 142 phase was $\mathrm{NaHCO}_{3} 0.8 \mathrm{mmol} \mathrm{L}-1+\mathrm{Na}_{2} \mathrm{CO}_{3} 2.9$ mmol L-1 prepared in nanopure water and 143 delivered at a flow rate of $0.7 \mathrm{~mL} \mathrm{~min}^{-1}$, while the sample injection volume was $100 \mu \mathrm{L}$. In these conditions sulfate was eluted at $25.5 \mathrm{~min}$ and had an average detection limit of $0.16 \mu \mathrm{mol} \mathrm{L}^{-1}$. 
145 The two IC systems provided reproducible and comparable results and were used 146 interchangeably for sulfate detection. The DX-320 instrument was also employed for the 147 detection of MSA in the model compounds experiments (12.5 min retention time in the 148 conditions described above), but it was unsuitable for MSA quantification in the natural water 149 experiments due to the relatively high detection limit $\left(0.37 \mu \mathrm{mol} \mathrm{L}{ }^{-1}\right)$. In addition, MSA analysis 150 was not possible with the Metrohm IC systems as MSA co-eluted with acetate, a common DOM 151 photolysis product. ${ }^{5}$

Total sulfur determination via ICP-MS/MS. Total sulfur concentrations were measured using an 153 Agilent 8900 inductively coupled plasma - tandem mass spectrometry (ICP-MS/MS) instrument equipped with a collision/reaction cell (C/RC) (Agilent Technologies, Switzerland). We used the integrated sample introduction system (ISIS), a Micromist nebulizer, a Scott double pass spray chamber, and platinum sampler and skimmer cones. Sulfur was detected in MS/MS mode using oxygen in the $\mathrm{C} / \mathrm{RC}$. The acquisition parameters were as follows: $m / z 32\left(\mathrm{MS}^{1}\right)-48\left(\mathrm{MS}^{2}\right)$, as $\mathrm{S}$ formed ${ }^{32} \mathrm{~S}^{16} \mathrm{O}^{+}$in the $\mathrm{C} / \mathrm{RC}$ in presence of oxygen, integration time $0.05 \mathrm{~ms}, 1$ point per peak, three replicates and 100 sweeps/replicate. All ICP-MS/MS parameters were optimized daily using a solution containing $1 \mu \mathrm{g} \mathrm{L}^{-1}$ of $\mathrm{Li}, \mathrm{Co}, \mathrm{Y}, \mathrm{Tl}$, and $\mathrm{Ce}$. Only the gas flow rate and the

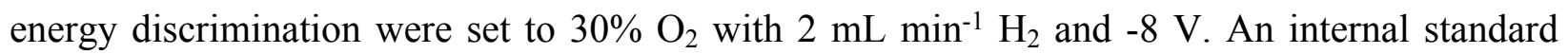
containing Sc $\left(1 \mathrm{mg} \mathrm{L}^{-1}\right)$, In $\left(1 \mathrm{mg} \mathrm{L}^{-1}\right)$ and $\mathrm{Lu}\left(1 \mathrm{mg} \mathrm{L}^{-1}\right)$ was used to check the stability of the signal during the runs. Quantification was done by external calibrations using standards prepared in nanopure water. The detection limit was $6 \mathrm{nmol} \mathrm{L}^{-1}$. The natural water samples were diluted to be in the concentration range of 1.2 to $0.012 \mu \mathrm{mol} \mathrm{L}-1$.

MSA, MSIA, DMSO quantification via HPLC-ICP-MS/MS. Sulfur speciation analysis via HPLCICP-MS/MS was performed using an Agilent 1200 series HPLC pump and the Agilent 8900 
ICP-MS/MS instrument described above. The chromatographic separation was performed with an Hypercarb 4.6x100 mm, particle size $5 \mu \mathrm{m}$ column (Thermo Fisher) and an elution gradient based on changes in formic acid concentration $\left(24-240 \mathrm{mmol} \mathrm{L}^{-1}\right)$. The mobile phase was delivered at $1 \mathrm{~mL} \min ^{-1}$ and the sample injection volume was $100 \mu \mathrm{L}$. As for total $\mathrm{S}$ quantification, S speciation was analyzed in MS/MS mode using oxygen in the $\mathrm{C} / \mathrm{RC}$, following the same tuning procedure and $\mathrm{C} / \mathrm{RC}$ settings. The acquisition parameters were $\mathrm{m} / \mathrm{z} 32-48$ and an integration time of $0.05 \mathrm{~ms}$. An internal standard containing $\mathrm{Sc}(5 \mathrm{mg} \mathrm{L}-1)$ and $\mathrm{Y}\left(5 \mathrm{mg} \mathrm{L}^{-1}\right)$ was delivered post-column using a T-connector and the peristaltic pump of the ICP-MS/MSThis allowed to monitor the signal stability during the analyses. Quantification of MSA and MSIA was done by external calibrations using standards prepared in nanopure water. Detection limits were $7 \mathrm{nmol} \mathrm{L}^{-1}$ for MSA and $38 \mathrm{nmol} \mathrm{L}^{-1}$ for MSIA. The experimental samples were analyzed undiluted.

Other analyses. Total non-purgeable organic carbon (TOC) was determined using a TOC analyzer (Shimadzu Corporation). PNA and pyridine concentrations were measured with a Waters ACQUITY UPLC system equipped with a C18 column (ACQUITY UPLC BEH 130 $\mathrm{C} 18,1.7 \mu \mathrm{m} ; 2.1 \times 150 \mathrm{~mm}$ ) and its guard column (ACQUITY UPLC BEH C18 VanGuard Precolumn, $130 \AA, 1.7 \mu \mathrm{m}, 2.1 \mathrm{~mm} \times 5 \mathrm{~mm})$. The analyses were performed in isocratic mode using a mixture of $40 \%$ acetate buffer $\mathrm{pH} 6(+10 \%$ acetonitrile) and $60 \%$ acetonitrile as eluent, a flow rate of $0.15 \mathrm{~mL} \mathrm{~min}^{-1}, 5 \mu \mathrm{L}$ injection volume and UV-Vis detection at 310 and $250 \mathrm{~nm}$ for PNA and pyridine, respectively. UV-Vis spectra were recorded with a Cary 100 Bio Spectrophotometer (Varian) using a $1 \mathrm{~cm}$ pathlength quartz cuvette in double beam mode.

\section{Data analysis}


190

191

192 sulfate concentration (Table S1).

$$
\Delta\left[\mathrm{SO}_{4}^{2-}\right]_{t}=\left[\mathrm{SO}_{4}^{2-}\right]_{t}-\left[\mathrm{SO}_{4}^{2-}\right]_{0}
$$

193 For each field-collected water or reference DOM sample, $\Delta\left[\mathrm{SO}_{4}{ }^{2-}\right]_{t}$ values from independent 194 triplicate experiments were averaged and the associated standard deviation was calculated. The 195 averaged $\Delta\left[\mathrm{SO}_{4}{ }^{2-}\right]_{t}$ values over 5 hours of UVB irradiation were fitted with a monoexponential 196 growth function (equation (6); see Results and Discussion) using a weighted non-linear fit

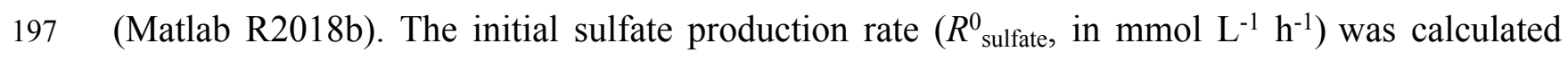
198 from the product of the fitting parameters (equation (7); see Results and Discussion). The initial 199 sulfate production quantum yield $\left(\Phi_{\text {sulfate }}^{0}\right)$ was obtained from the same dataset using as $\mathrm{X}$-axis 200 the absorbed photons instead of the time (Supplementary Text S5).

201 For the 5-hour time point, the fraction of the initial DOS converted to sulfate $\left(f_{\text {sulfate, } 5 \mathrm{~h}}\right)$ was 202 calculated according to equation (2).

$$
f_{\text {sulfate, } 5 \mathrm{~h}}=\frac{\Delta\left[\mathrm{SO}_{4}^{2-}\right]_{5 \mathrm{~h}}}{[\mathrm{DOS}]_{0}}
$$

203 where $\Delta\left[\mathrm{SO}_{4}^{2-}\right]_{5 \mathrm{~h}}$ is the photoproduced sulfate according to equation (1) and [DOS $]_{0}$ is the initial 204 DOS concentration. [DOS $]_{0}$ was calculated according to equation (3), ${ }^{18,19}$ where $[\mathrm{S}]_{0}$ was 205 obtained via ICP-MS/MS and $\left[\mathrm{SO}_{4}{ }^{2-}\right]_{0}$ via ion chromatography, and ranged from 3.3 to $34 \mu \mathrm{mol}$ 206 L $^{-1}$ (Table S2).

$$
[\mathrm{DOS}]_{0}=[\mathrm{S}]_{0}-\left[\mathrm{SO}_{4}^{2-}\right]_{0}
$$


207 The product distribution was calculated according to equation (4), where [volatiles] $]_{5 \mathrm{~h}}=1-$ $208[\mathrm{~S}]_{5 \mathrm{~h}} /[\mathrm{S}]_{0}$. Note that $[\text { volatiles }]_{5 \mathrm{~h}}$ was set to zero if $[\mathrm{S}]_{5 \mathrm{~h}} /[\mathrm{S}]_{0}+$ error $\geq 1$ (the error is the standard 209 deviation of triplicate experiments).

$$
\% \mathrm{X}=\frac{[\mathrm{X}]_{5 \mathrm{~h}}}{\Delta\left[\mathrm{SO}_{4}^{2-}\right]_{5 \mathrm{~h}}+[\mathrm{MSA}]_{5 \mathrm{~h}}+[\mathrm{MSIA}]_{5 \mathrm{~h}}+[\text { volatiles }]_{5 \mathrm{~h}}}
$$

Model compounds experiments. In the model compounds experiments, sulfate photoproduction

212 was corrected for the background of the natural sensitizer (DS2014) according to equation (5).

$$
\left[\mathrm{SO}_{4}^{2-}\right]_{c o r r, t}=\Delta\left[\mathrm{SO}_{4}^{2-}\right]_{t}-\Delta\left[\mathrm{SO}_{4}^{2-}\right]_{t, \mathrm{DS} 2014}
$$

where $\Delta\left[\mathrm{SO}_{4}{ }^{2-}\right]_{t, \mathrm{DS} 2014}$ is the photoproduced sulfate at time $t$ generated from the natural sensitizer

214 in the absence of amendments. The MSA data were not corrected due to the negligible 215 background from the natural sensitizer in the concentration range of interest.
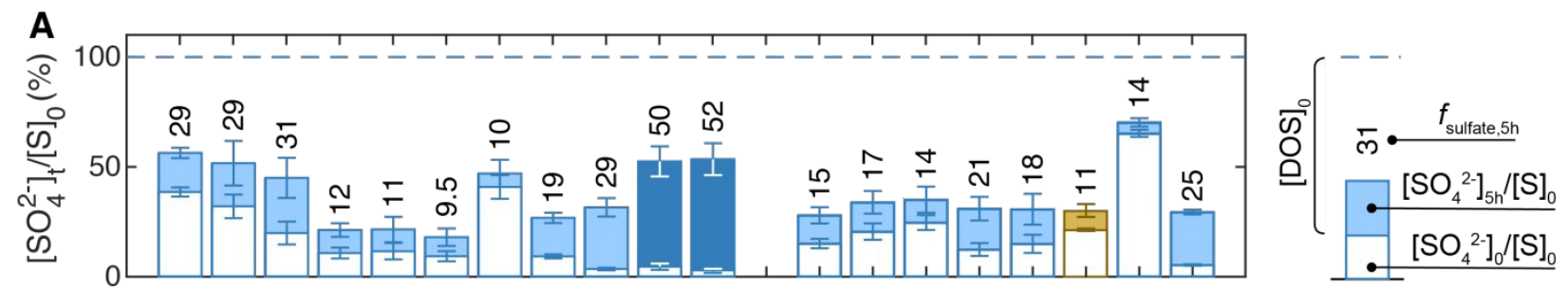

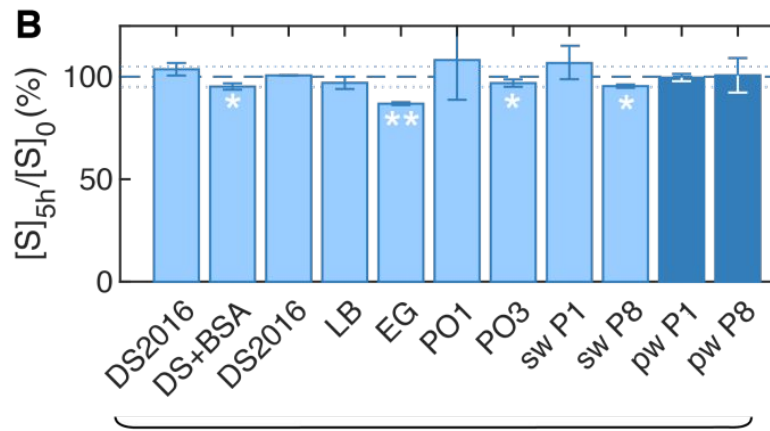

Field-collected DOM
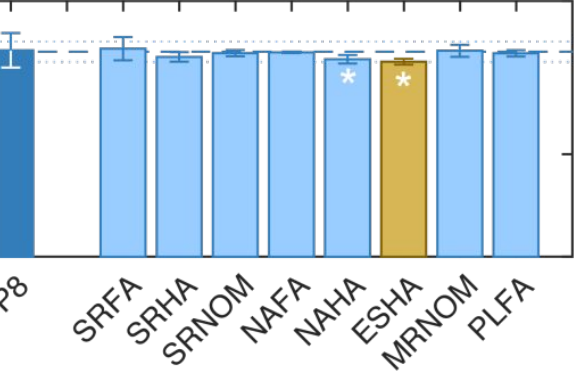

Reference DOM (IHSS) 
Figure 1 Photochemically induced changes in sulfur speciation in reference and fieldcollected DOM samples. A. White and blue bars represent $[\mathrm{S}]_{0}$-normalized sulfate concentrations at the beginning and at the end of the irradiation, respectively. The numbers above the bars indicate the fraction of $[\mathrm{DOS}]_{0}$ converted to sulfate after 5 hours of UVB irradiation $\left(f_{\text {sulfate }, 5 \mathrm{~h}}\right)$. The error bars are obtained from error propagation of the standard deviations in $[\mathrm{S}]_{0},\left[\mathrm{SO}_{4}{ }^{2-}\right]_{0}$ and $\left[\mathrm{SO}_{4}{ }^{2-}\right]_{5 \mathrm{~h}}$ (triplicate measurements). In these experiments, 5 hours of irradiation were approximately equivalent to 11 hours during a clear midsummer day (Supplementary Text S3; $I=65 \pm 4 \mathrm{~J} \mathrm{~s}^{-1} \mathrm{~m}^{-2}$ ). B. Changes in total sulfur during UVB irradiation experiments. The error bars are standard deviations of independent triplicate experiments, while the asterisk(s) indicates samples with $[\mathrm{S}]_{5 \mathrm{~h}} /[\mathrm{S}]_{0}$ ( \pm error) below unity $(*=$ value within $5 \%$; $* *=$ value within $10 \%)$. In these experiments, the absolute irradiance was $46 \pm 5 \mathrm{~J} \mathrm{~s}^{-1} \mathrm{~m}^{-2}(\Delta \lambda=290-$ $400 \mathrm{~nm})$. The acronyms for the waters can be found in Table S1, while the numeric values of $f_{\text {photo,5h }}$ and $[\mathrm{S}]_{5 \mathrm{~h}} /[\mathrm{S}]_{0}$ and their associated experimental errors are in Table $\mathrm{S} 2$ and $\mathrm{S} 3$, respectively.

\section{Results and discussion}

Photochemical production of sulfate from DOS

Aqueous solutions of reference DOM isolates from soil, river and lakes and field-collected natural waters from lakes, swamps and peat bogs were irradiated with UVB light under laboratory conditions, and sulfate photoproduction was quantified via ion chromatography (Figure S5). This collection of materials was chosen to reflect a wide range of natural DOM variability, from terrestrially- (i.e., Dismal Swamp; DS) to microbially-derived (i.e., Pony Lake fulvic acid; PLFA) organic matter end members, ${ }^{20,21}$ as can be inferred, for example, from the 242 relatively wide range of $\mathrm{SUVA}_{254}$ values of our samples (Table S1). We focused on freshwater environments due to the analytical challenges of detecting small sulfate variations in the large sulfate background typical of marine samples, and on the lack of easily accessible marine reference material. The lamp spectrum shows a reasonable Gaussian distribution centered around $310 \mathrm{~nm}$, with a shorter wavelength cut-off of $280 \mathrm{~nm}$ (Figure S1). Wavelengths $<290 \mathrm{~nm}$ accounted only for $1.6 \%$ of total lamp irradiance, implying that the photochemical processes observed in our work are mainly triggered by environmentally relevant wavelengths. 
Overall, 10 to $50 \%$ of the initial DOS was mineralized to sulfate after an irradiation period approximately equivalent to a whole clear midsummer day $\left(f_{\text {sulfate, } 5 \mathrm{~h}}\right.$, Figure $\left.1 \mathrm{~A}\right)$, even though variations were observed across samples. Significantly higher $f_{\text {sulfate, } 5 \mathrm{~h}}$ values were obtained for the Prairie Pothole porewaters (50 $\pm 5 \%$ and $52 \pm 4 \%$ ) compared to the surface waters of the corresponding pools $(19 \pm 1 \%$ and $29 \pm 4 \%$, respectively), which exhibited photochemical behavior analogous to the other field-collected surface waters and the reference DOM samples $\left(f_{\text {sulfate }, 5 \mathrm{~h}} \approx 10-30 \%\right)$. Smaller variations could also be identified within the surface water samples. For instance, $f_{\text {sulfate, } 5 \mathrm{~h}}$ values of the Prairie Pothole surface waters, the three DS samples and PLFA were overall higher than the other samples $(27 \pm 4 \%(N=6)$ vs $14 \pm 3 \%(N=11))$. We speculate that the higher mineralized fractions in these waters may be due to specific characteristics of these three environments. Sleighter et al. showed that diagenetic sulfurization occurs in the Prairie Pothole sediments, resulting in the formation of an abundant pool of Senriched DOM that is not found in typical lacustrine environments, ${ }^{22}$ as confirmed by the low DOC/DOS ratios of the porewaters compared to the other samples (Table S2). Water circulation within the wetland brings the S-enriched DOS from the sediments to the surface, ${ }^{22,23}$ where oxidative transformations can occur ${ }^{11,23}$. Thus, we reason that the Prairie Pothole surface waters are more reactive than common surface waters due to a higher content of organic sulfur, but less reactive than the corresponding porewaters due to a lower fraction of reduced sulfur species. Dismal Swamp is characterized by a relatively high iron content and high hydroxyl radical steady-state concentrations (during irradiation), ${ }^{24}$ which may trigger DOS degradation mechanisms that would otherwise be of limited relevance. Finally, the higher photochemical reactivity of PLFA might be related to its molecular composition, which is dominated by bacterial- and algal-derived organic matter. ${ }^{20}$ This difference in source material compared to 
272 terrestrially-derived DOM might result in a different distribution of S oxidation states, an 273 increased photochemical reactivity (already documented for triplet DOM-related processes) ${ }^{25}$, or 274 a combination of these two factors.

275 To test whether complete photomineralization can occur, long-term irradiations were also 276 performed on PLFA and DS water (Figure 2A and S6A, respectively). Both samples showed a 277 clear plateau in sulfate production, with a fractional yield ( $Y_{\text {sulfate }}$; see below) of $67 \%$ and $85 \%$ 278 for PLFA and DS, respectively. This result indicates that the majority, but not all, of $[\mathrm{DOS}]_{0}$ 279 could be converted to sulfate, suggesting that photorefractory (i.e., photochemically stable) 280 compounds might be present before or might be formed during irradiation. Furthermore, in 281 PLFA, the plateau was observed when sulfate production was plotted vs absorbed photons 282 (Figure 2A), while in DS the plateau was observed when using irradiation time as X-axis (Figure 283 S6A). The difference between irradiation time and absorbed photons is related to 284 photobleaching, i.e. the destruction of chromophores, which is a well-known process in DOM 285 photochemistry. ${ }^{26}$ Photobleaching was observed for both waters (Figure S6B), but appeared to 286 limit sulfate production for PLFA only, hinting that different sulfate production mechanisms 287 might be active in the two samples.

288 For more insight into the sulfate production mechanisms, we analyzed the sulfate 289 photoproduction kinetics and tested for correlations with relevant water chemistry parameters. 290 We fitted the sulfate concentration profiles with an exponential growth function (equation (6); 291 Figure S5), where the pre-exponential term is proportional to [DOS $]_{0}$ via the constant $Y_{\text {sulfate, }}$ and $292 k$ is the apparent pseudo-first-order rate constant. We defined $Y_{\text {sulfate }}$ as the fractional yield of 293 sulfate, thus the moles of sulfate produced per mole of DOS that reacts. 


$$
\Delta\left[\mathrm{SO}_{4}^{2-}\right]_{t}=\left[\mathrm{SO}_{4}^{2-}\right]_{t}-\left[\mathrm{SO}_{4}^{2-}\right]_{0}=[\mathrm{DOS}]_{0} Y_{\text {sulfate }}\left(1-e^{-k t}\right)
$$

Apparent first-order kinetic behavior is a common feature of complex chemical mixtures, ${ }^{27}$ and has already been reported for $\mathrm{DOC}^{28}$. For each field-collected and reference DOM sample, the initial sulfate production rate $\left(R_{\text {sulfate, in } \mu \mathrm{mol} \mathrm{L}}^{-1} \mathrm{~h}^{-1}\right)$, which is defined as the product of the initial rate of light absorption $\left(R_{\text {abs }}^{0}\right)$ and the quantum yield of sulfate production $\left(\Phi_{\text {sulfate }}\right)$, was calculated according to equation (7) using the parameters obtained from the non-linear fit.

$$
R_{\text {sulfate }}^{0}=R_{a b s}^{0} \Phi_{\text {sulfate }}=k Y_{\text {sulfate }}[\mathrm{DOS}]_{0}
$$

$R_{\text {sulfate }}^{0}$ varied among the nineteen samples both as a function of $[\mathrm{DOS}]_{0}$ and as a function of the apparent rate constant (Table S2). Despite of these variations, a significant correlation was found between $R^{0}$ sulfate and [DOS $]_{0}$ when excluding the porewater samples $\left(N=17, \mathrm{R}^{2}=0.95\right.$; Figure 2B), revealing that the photochemical reactivity of DOS is overall comparable across a wide range of environments. The porewater samples displayed higher apparent rate constants, further confirming the high photochemical reactivity of DOS in these samples in correlation with the increased proportion of reduced S species (see above).

The same trend reported in Figure 1B was observed when the initial sulfate production quantum yield ( $\Phi_{\text {sulfate, }}^{0}$ i.e., moles of sulfate produced per moles of photons absorbed) was plotted against $[\mathrm{DOS}]_{0}$ (Figure S7A). The fact that $\Phi_{\text {sulfate }}^{0}$ (thus $R_{\text {sulfate }}^{0}$ see equation (7)) depends on [DOS $]_{0}$ can be justified considering some basic principles of photochemical kinetics. We reasoned that whether sulfate is produced via direct or indirect photolysis, its quantum yield is expected to increase linearly with $[\mathrm{DOS}]_{0}$. For instance, for a generic indirect process mediated by a photochemically produced reactive intermediate (PPRI), $\Phi_{\text {sulfate }}$ can be described by the following equation. 


$$
\Phi_{\text {sulfate }}=\Phi_{\mathrm{PPRI}} \cdot \frac{k_{r x n, \mathrm{DOS}}^{\mathrm{PPRI}}[\mathrm{DOS}]_{0}}{k_{d}^{\mathrm{PPRI}}} \cdot Y_{\text {sulfate }}^{\mathrm{PPRI}}
$$

314 where $\Phi_{\text {PPRI }}$ is the PPRI production quantum yield, $k^{\text {PPRI }}{ }_{r x n, \text { DOS }}$ is the bimolecular rate constant

315 for the reaction with DOS, $k^{\mathrm{PPRI}}$ is the total deactivation rate constant, and $Y^{\mathrm{PPRI}}{ }_{\text {sulfate }}$ is the

316 fractional yield of sulfate formed via reaction with PPRI. Comparable equations can be derived

317 for direct photolysis or for a combination of direct and indirect photolysis (Supplementary Text 318 S6).

Photochemical production of other S-containing low-molecular-weight compounds from

321 DOS

322 To investigate whether other non-volatile DOS products are formed during UVB irradiation, the

323 samples were also analyzed by high-performance liquid chromatography coupled to inductively

324 coupled plasma - tandem mass spectrometry (HPLC-ICP-MS/MS). We found methanesulfonic

325 acid (MSA) to be a common DOS photodegradation product, given its detection in all irradiated

326 samples at concentrations ranging from $12.6 \pm 0.8 \mathrm{nmol} \mathrm{L}^{-1}$ (PO3) to $300 \pm 30 \mathrm{nmol} \mathrm{L}^{-1}$ (pw P8).

327 Similarly, methanesulfinic acid (MSIA) was observed in seventeen out of nineteen samples at

328 concentrations up to 10 times higher than MSA (Table S3). Furthermore, some of the samples

329 with the highest $[\mathrm{DOS}]_{0}$ showed few additional peaks in their chromatograms that were not

330 present before irradiation (Table S3). Even though we did not identify these additional products,

331 this result hints that sub-nanomolar concentrations of other S-containing compounds might also

332 be produced in samples with lower $[\mathrm{DOS}]_{0}$. Finally, dimethyl sulfoxide (DMSO), a known 
333 aqueous-phase DMS photooxidation product, ${ }^{1,15}$ was never detected after irradiation, which fits 334 the view that DMSO is a DMS-specific photooxidation product.

335 Total sulfur was also quantified by ICP-MS/MS before and after UVB irradiation in order to 336 estimate the relative importance of volatile vs non-volatile organosulfur products. Indeed, COS 337 and $\mathrm{CS}_{2}$ are the only (non-DMS) DOS photoproducts that have been reported in the literature so 338 far. ${ }^{1,19,29-33}$ Studies of $\mathrm{COS}$ and $\mathrm{CS}_{2}$ photoproduction are mostly limited to coastal and open 339 ocean environments, with a single work investigating a freshwater system (an artificial lake). ${ }^{9}$ 340 Based on this latter publication and on mechanistic studies showing COS production from the 341 DOM-photosensitized degradation of cysteine, glutathione and other thiols, ${ }^{34-38}$ which are 342 ubiquitous compounds in the environment (Table S4 and references therein), we anticipated that 343 these volatile compounds should also be formed (and lost to the headspace) during our 344 irradiation experiments. The resulting mass balances, expressed as $[\mathrm{S}]_{5 \mathrm{~h}} /[\mathrm{S}]_{0}$ ratio, were complete 345 for most of the samples, indicating that $\mathrm{COS}$ and $\mathrm{CS}_{2}$ were at most minor products (Table $\mathrm{S} 3$ and 346 Figure 1B). The only notable exception was the samples collected from Étang de la Gruère, 347 which had a $[\mathrm{S}]_{5 \mathrm{~h}} /[\mathrm{S}]_{0}$ value considerably lower than unity $(0.87 \pm 0.01)$. Unfortunately, the 348 relatively high experimental error of our method provides only an estimate of the contribution of 349 volatile species to the inventory of DOS photoproducts. Future studies based on direct gas 350 measurements would be needed to accurately quantify photochemical production of COS and $351 \quad \mathrm{CS}_{2}$ in freshwater environments.

352 In order to understand the relative importance of each degradation pathway, we estimated the 353 product distribution in each DOM sample (Figure 2C and Table S3). Note that, due to the 354 relatively high experimental errors, volatile product contributions were considered only if $355[\mathrm{~S}]_{5 \mathrm{~h}} /[\mathrm{S}]_{0}+$ error $<1$. Overall, sulfate was the main photoproduct, representing $28-94 \%$ of the 
356

357

358

359

360

361

362

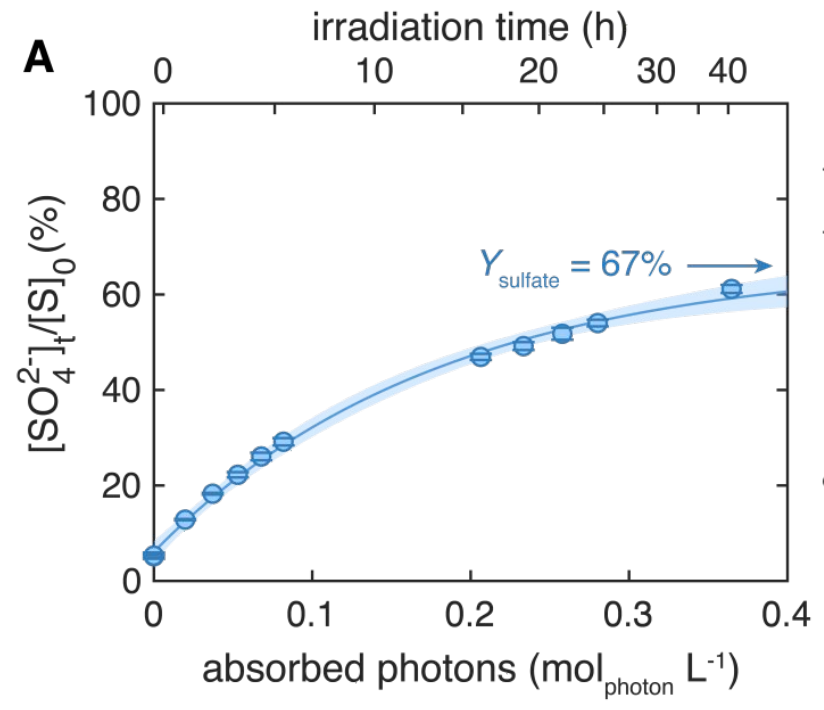

C

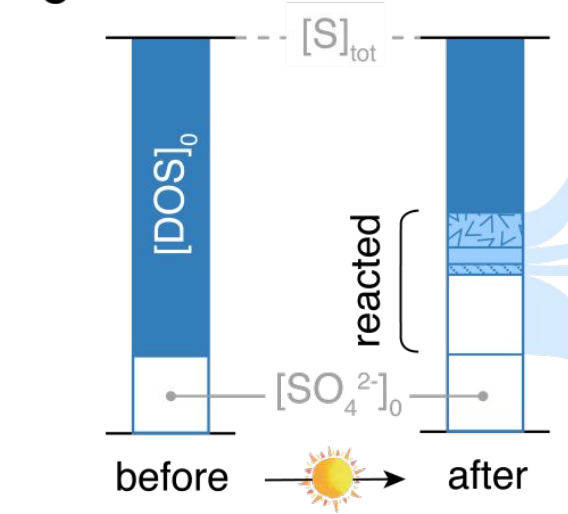

363

364

365

366

367 DOC photoproduct. ${ }^{39}$

reacted DOS pool, with a median value of $75 \%$. MSIA and MSA were $0-39 \%$ (median: $14 \%$ ) and $1.2-8 \%$ (median: $3.4 \%$ ) of the products, respectively. In the six (of nineteen) samples where the mass balance was significantly different from $100 \%$ (indicating that $\mathrm{S}$ was lost to volatile products) the volatile species represented $15-71 \%$ of the reacted pool (median: $34 \%$ ).

These results mirror the behavior of DOC, as $\mathrm{CO}_{2}$, the highest oxidation state product, is released approximately 2 to more than 65 times more effectively than $\mathrm{CO}$, the second most abundant
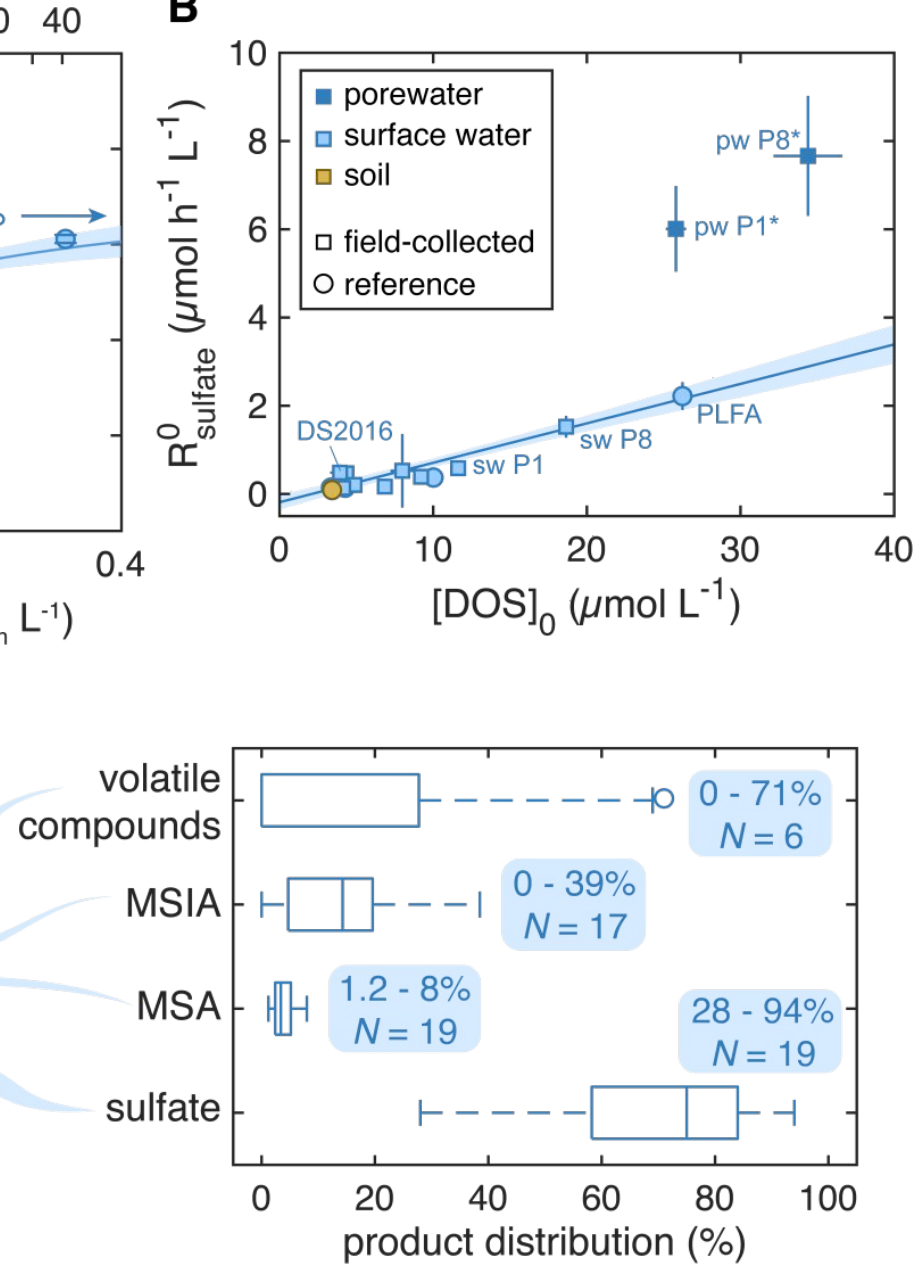

Figure 2 Long-term PLFA degradation kinetics, and sulfate, MSA and MSIA production from naturally-occurring DOS. A Long-term photomineralization for PLFA. The derivation of the lower x-axis (absorbed photons) is described in the Supplementary Text S5. The error bars are standard deviations of triplicate experiments. B Linear regressions of $R_{\text {sulfate }}^{0} v s[\mathrm{DOS}]_{0}$ for 
the field-collected (squares) and reference (circles) surface water and soil DOM $\left(\mathrm{R}^{2}=0.95, N=\right.$ 17 , slope $\left.=(0.089 \pm 0.005) \mathrm{h}^{-1}\right)$. The porewater samples (blue filled squares) are excluded from the fit. When not visible, the error bars are within the symbols. Numerical values of $R^{0}$ sulfate and $[\mathrm{DOS}]_{0}$ and their associated errors are listed in Table S2. C Box plot showing the products distribution for the nineteen samples investigated. The numbers in blue show the ranges for each single product, while $N$ indicates the number of DOM samples in which the product was observed after irradiation. The numerical values for each DOM sample are listed in Table S3.

\section{Environmentally relevant molecular precursor of sulfate and MSA}

To identify possible molecular precursor substrates for sulfate and MSA production, twenty-two organic sulfur model compounds (Figure S8) were irradiated with UVB light in the presence of a natural sensitizer (Dismal Swamp water), and both sulfate and MSA were quantified via ion chromatography (Table 1 and Figure S9). The model compounds were selected based on the oxidation state of the $\mathrm{S}$ atom(s) and the aliphatic/aromatic nature of the carbon scaffold. Specifically, we focused on the three most abundant $\mathrm{S}$ oxidation states found in natural organic matter (Figure S10 and references therein), namely S(-II) (thiols, thioethers and thiophenes), $\mathrm{S}(+\mathrm{IV})$ (sulfonic acids) and $\mathrm{S}(+\mathrm{VI})$ (organosulfates). For each S oxidation state, several aromatic and aliphatic compounds were selected in order to test whether the molecular structure influences the photochemical fate of the $\mathrm{S}$ atom(s). Altogether, this collection of model compounds includes molecules that have already been detected in the environment or that might be present in DOS with a modified carbon scaffold (Tables S4-S5).

Table 1 Photosensitized production of sulfate and MSA from individual model compounds. Summary of sulfate and MSA concentrations detected after 2 hours of UVB irradiation $\left(I_{\lambda}=65 \pm\right.$ $\left.4 \mathrm{~J} \mathrm{~s}^{-1} \mathrm{~m}^{-2}\right)$ in the presence of an individual model compound $\left(50 \mu \mathrm{mol} \mathrm{L}^{-1}\right)$ and a natural sensitizer (Dismal Swamp water). The molecular structures are provided in Figure S8, and the 5hour irradiation kinetics in Figure S9. N.D. = no peak detected; N.S. = non-significant $\left(\left[\mathrm{SO}_{4}{ }^{2-}\right.\right.$ ]$_{c o r r, 2 \mathrm{~h}}<0.0 \pm 0.2 \mu \mathrm{mol} \mathrm{\textrm {L } ^ { - 1 } ) .}{ }^{a}$ Hybridization of carbon atoms bound to sulfur referred to as aliphatic $\left(\mathrm{sp}^{3}\right)$ or aromatic $\left(\mathrm{sp}^{2}\right)$ in the main text. ${ }^{b}$ Corrected for the sulfate produced by the natural sensitizer. ${ }^{c}+=$ detected in the environment (references in Table S4); ${ }^{*}=$ surrogate for $\mathrm{S}$-containing functional groups present in environmental systems (see Table $\mathrm{S} 5$ for examples). ${ }^{d}$ $50 \mathrm{mg}_{\mathrm{C}} \mathrm{L}^{-1}$ addition of bovine serum albumin is equivalent to $\approx 25 \mu \mathrm{mol}_{\mathrm{S}} \mathrm{L}^{-1}$. 


\begin{tabular}{|c|c|c|c|c|}
\hline Compound & $\begin{array}{c}\mathrm{C} \\
\substack{a \\
\text { hybridization }}\end{array}$ & $\begin{array}{l}{\left[\mathrm{SO}_{4}{ }^{2-}\right]_{c o r r}, 2 \mathrm{~h}} \\
\left(\mu \mathrm{mol} \mathrm{\textrm {L } ^ { - 1 }}\right)^{b}\end{array}$ & $\begin{array}{c}{\left[\mathrm{MSA}_{2 \mathrm{~h}}\right.} \\
\left(\mu \mathrm{mol} \mathrm{L}{ }^{-1}\right)\end{array}$ & $\begin{array}{l}\text { Environmental } \\
\text { occurrence }^{c}\end{array}$ \\
\hline \multicolumn{5}{|c|}{ S(-II): Thiols, thioethers and thiophenes } \\
\hline Cysteine & $\mathrm{sp}^{3}$ & $2.2 \pm 0.2$ & N.D. & + \\
\hline Methionine & $\mathrm{sp}^{3}$ & $1.87 \pm 0.03$ & $1.97 \pm 0.02$ & + \\
\hline Glutathione & $\mathrm{sp}^{3}$ & $2.5 \pm 0.4$ & N.D. & + \\
\hline Bovine serum albumin ${ }^{d}$ & $\mathrm{sp}^{3}$ & $\mathbf{1 . 1} \pm 0.4$ & N.D. & $*$ \\
\hline 3-Mercaptopropionic acid & $\mathrm{sp}^{3}$ & $\mathbf{1 . 0 8} \pm 0.02$ & N.D. & + \\
\hline Biotin & $\mathrm{sp}^{3}$ & $2.6 \pm 0.2$ & N.D. & + \\
\hline Thioacetamide & $\mathrm{sp}^{2}$ & $7.3 \pm 0.3$ & N.D. & $*$ \\
\hline $\begin{array}{l}\text { 3-(Methylthio)benzoic } \\
\text { acid }\end{array}$ & $\mathrm{sp}^{2} / \mathrm{sp}^{3}$ & $\mathbf{0 . 2 5} \pm 0.05$ & $4.5 \pm 0.8$ & $*$ \\
\hline Thioanisole & $\mathrm{sp}^{2} / \mathrm{sp}^{3}$ & $\mathbf{1 . 0 0} \pm 0.02$ & $\mathbf{0 . 6 2} \pm 0.01$ & + \\
\hline 3-Mercaptobenzoic acid & $\mathrm{sp}^{2}$ & $\mathbf{3 . 4} \pm 0.3$ & N.D. & $*$ \\
\hline 2,2'-Bithiophene & $\mathrm{sp}^{2}$ & $\mathbf{2 0} \pm 3$ & N.D. & $*$ \\
\hline \multicolumn{5}{|l|}{ S(+IV): Sulfonic acids } \\
\hline Cysteinesulfonic acid & $\mathrm{sp}^{3}$ & N.S. & N.D. & $*$ \\
\hline Methanesulfonic acid & $\mathrm{sp}^{3}$ & N.S. & N.D. & + \\
\hline 1-Hexanesulfonic acid & $\mathrm{sp}^{3}$ & N.S. & N.D. & $*$ \\
\hline $2-($ & $\mathrm{sp}^{3}$ & N.S. & N.D. & $*$ \\
\hline \multicolumn{5}{|l|}{$\begin{array}{l}\text { Cyclohexylamino)ethane } \\
\text { sulfonic acid }\end{array}$} \\
\hline Taurocholic acid & $\mathrm{sp}^{3}$ & N.S. & N.D. & $*$ \\
\hline Benzenesulfonic acid & $\mathrm{sp}^{2}$ & $\mathbf{1 . 5} \pm 0.1$ & N.D. & $*$ \\
\hline 4-Toluenesulfonic acid & $\mathrm{sp}^{2}$ & $4.3 \pm 0.2$ & N.D. & + \\
\hline $\begin{array}{l}\text { 1,2-Naphthoquinone-4- } \\
\text { sulfonic acid }\end{array}$ & $\mathrm{sp}^{2}$ & $35 \pm 2$ & N.D. & $*$ \\
\hline $\begin{array}{l}\text { 4-Dodecylbenzenesulfonic } \\
\text { acid }\end{array}$ & $\mathrm{sp}^{2}$ & $1.2 \pm 0.1$ & N.D. & + \\
\hline \multicolumn{5}{|l|}{ S(+VI): Organosulfates } \\
\hline Pregnenolone sulfate & - & $\mathbf{3 . 0} \pm 0.1$ & N.D. & $*$ \\
\hline 4-Nitrocatechol sulfate & - & $3.7 \pm 0.1$ & N.D. & $*$ \\
\hline
\end{tabular}

401 Nearly all model compounds could be photomineralized to sulfate, albeit with different kinetics 402 and different yields (Figure S9). The aliphatic sulfonic acids were the only molecules that 403 showed no sulfate production. In two cases (cysteinesulfonic acid and MSA), we could 
404 experimentally confirm the photochemical stability of the parent compound ([MSA $]_{5 h} /[\mathrm{MSA}]_{0 \mathrm{~h}}=$ $\left.1.00 \pm 0.06 ;\left[\mathrm{CysSO}_{3} \mathrm{H}\right]_{5 \mathrm{~h}} /\left[\mathrm{CysSO}_{3} \mathrm{H}\right]_{0 \mathrm{~h}}=1.03 \pm 0.04\right)$, providing good support for the hypothesis that the incomplete conversion of DOS to sulfate can also be due to the initial presence and/or formation of photochemically stable DOS components. Such photorecalcitrant molecules can be produced from biological activity (i.e. cysteinesulfonic acid) ${ }^{40}$ or could be formed during DOS photodegradation (i.e. MSA). In addition, MSA was always formed during the photodegradation of methyl thioethers, suggesting that methionine and other naturally occurring methyl thioethers can be the precursors of MSA. In one case, MSA was produced in higher yields than sulfate (3(methylthio)benzoic acid: $\left[\mathrm{SO}_{4}{ }^{2-}\right]_{\mathrm{corr}, 2 \mathrm{~h}}=0.25 \pm 0.05 \mu \mathrm{mol} \mathrm{L}-1 ;[\mathrm{MSA}]_{2 \mathrm{~h}}=4.5 \pm 0.8 \mu \mathrm{mol} \mathrm{L}^{-1}$ ), reinforcing the idea that sulfate is not necessarily the only photodegradation product of DOS.

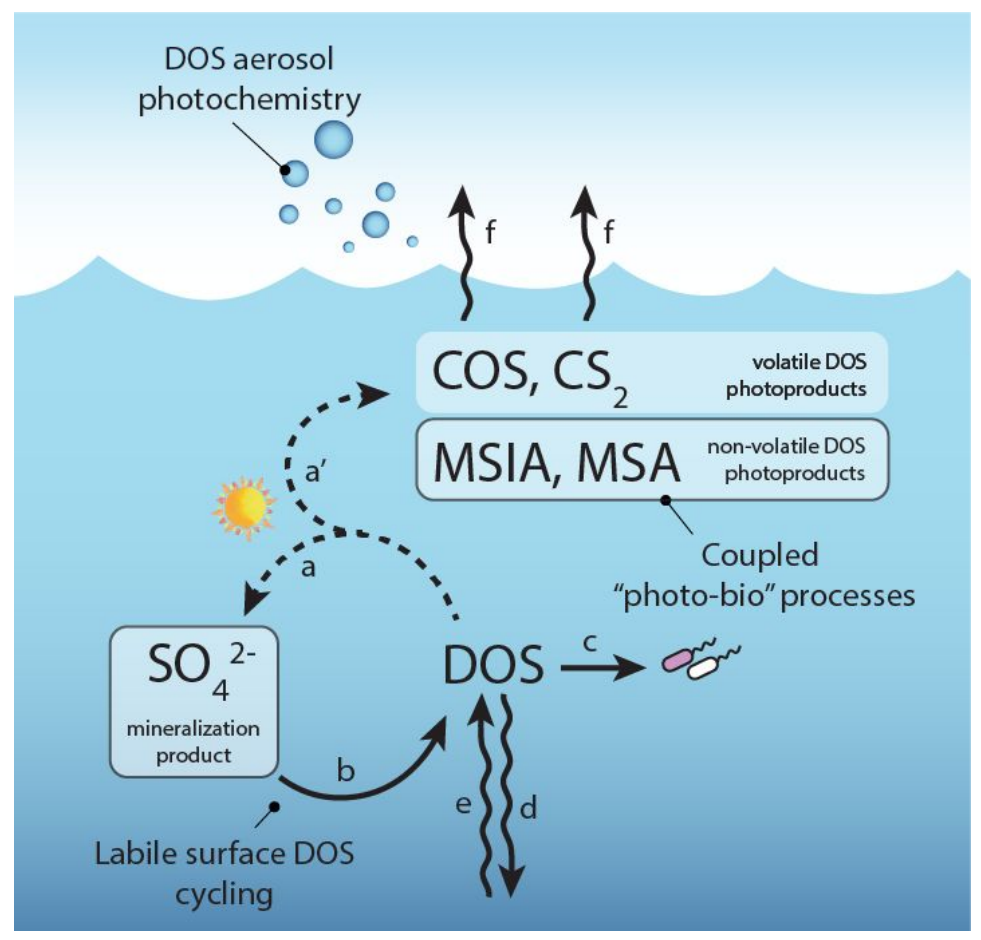


419 Legend: $a$. photomineralization; $a^{\prime}$. photofragmentation; $b$. sulfate assimilation and DOS release 420 from phytoplankton; $c$. microbial DOS uptake; $d$. downwelling; $e$. upwelling; $f$. outgassing.

\section{Implications and open questions}

Our study reports direct evidence of sulfate production from the photochemical degradation of dissolved organic sulfur from a variety of natural freshwater samples (Figure 3). This finding fills in the general picture of the role of photochemistry on the biogeochemical cycle of the main elements, showing that, similar to dissolved organic carbon, ${ }^{1}$ nitrogen ${ }^{6,7}$ and phosphorous ${ }^{8}$, also DOS can be converted to its inorganic form via photochemical routes.

In addition, the identification of a photomineralization mechanism provides a more complete picture on the biogeochemistry of DOS. Only few studies on DOS photodegradation can be found in the literature, ${ }^{11,12,14}$ which focused on the loss of DOS formulas via HRMS, and not on the identification of the S-containing products. The inverse is true for the studies of photochemical formation of $\operatorname{COS}$ and $\mathrm{CS}_{2}$ in the natural environment, ${ }^{1,19,29-33}$ which described the appearance of products with no clear link made to loss of DOS. Our work provides a bridge between these two research themes. First, it suggests that sulfate is the most likely product associated to the loss of DOS observed in the HRMS studies. For instance, Gomez-Saez et al. reported up to $\approx 30 \%$ of $[\mathrm{DOS}]_{0}$ loss after 2 days of solar irradiation in saltmarsh porewater samples. Even though care should be taken when comparing results obtained with different light sources, this number qualitatively agrees with the high mineralized fractions (i.e. DOS conversion to sulfate) that we observed for our porewater samples $\left(f_{\text {photo, } 5 \mathrm{~h}}=50-52 \%\right)$. Second, the present work gives a sense of the relative importance of the different degradation pathways. In particular, we found that sulfate is often the main photodegradation product, while the other volatile $\left(\mathrm{COS}, \mathrm{CS}_{2}\right)$ and non-volatile (MSA, MSIA) low-molecular-weight compounds are 
443 quantitatively less important in terms of mass balance. These results echo the observation that $444 \mathrm{CO}_{2}$, the most oxidized carbon form, is the most abundant DOC photodegradation product. ${ }^{1}$ Our 445 results are directly relevant to aquatic terrestrial organic matter in freshwater systems, but we 446 expect them to hold valid also for marine DOM. Control experiments showed no suppression in 447 sulfate production at high ionic strength and low DOC concentrations, which are conditions 448 typical of marine environments (Supplementary Text S4). In addition, preliminary results with a 449 marine DOM sample collected in the Pacific Ocean were found in good agreement with the 450 findings presented in this work for terrestrial DOM and for Pony Lake fulvic acid 451 (Supplementary Text S4), which has been used by other authors as a surrogate for marine $\mathrm{DOM}^{21}$. As a further point, model compounds able to produce both sulfate and COS are present in both terrestrial and marine environments (Table S4). For instance, glutathione, which can 454 produce both $\operatorname{COS}^{35,38}$ and sulfate (see above), is commonly found in freshwater, ${ }^{41}$ estuaries $^{42}$ 455 and in the open ocean ${ }^{43}$. Nevertheless, further studies need to experimentally confirm the 456 production of sulfate and non-volatile low-molecular-weight compounds from marine DOS 457 photolysis.

458 The facile conversion of DOS to sulfate and MSA described here puts the DOS cycle into a new perspective, providing possible answers to the many unresolved questions on its biogeochemistry 460 and suggesting new research directions (Figure 3). For example, photomineralization can be a 461 potential explanation for the fast DOS turnover described by Ksionzek et al. in the mixed surface 462 layer of the ocean. ${ }^{18}$ In particular, we anticipate that autochthonous DOS released by 463 phytoplankton at the surface (i.e. glutathione and other peptides) can be converted to sulfate 464 upon DOM-sensitized photolysis. In addition, photochemistry can play a role in converting 465 biologically refractory DOS components into bioavailable substrates, similarly to what happens 
466 for carbon cycling. ${ }^{1,44}$ Indeed, microorganisms able to use MSA either as a S-source, a C-source 467 or an energy source have been identified in a variety of environments ${ }^{45,46}$ and were recently 468 found to be abundant in surface seawater ${ }^{47}$. Lastly, we hypothesize that non-DMS sulfur 469 compounds present in aerosols, such as organosulfates, ${ }^{48}$ cysteine- and methionine-containing 470 peptides and proteins, ${ }^{49}$ might degrade to sulfate via aqueous-phase photochemical reactions 471 sensitized by organic chromophores, similar to what we report here for bulk solutions. Thus, 472 atmospheric DOS might be an aqueous-phase precursor of non-sea-salt sulfate, an important 473 contributor to aerosol formation in remote marine areas. ${ }^{50,51}$ Photosensitized oxidations can also 474 represent an additional route to convert other atmospherically relevant inorganic S species, such 475 as $\mathrm{SO}_{2} / \mathrm{SO}_{3}{ }^{2-}$, to sulfate (Figure $\mathrm{S} 11$ ). This photosensitized process, together with other water476 phase reactions involving reactive nitrogen species, ${ }^{52,53}$ might contribute to the high sulfate 477 levels observed during severe urban haze events, which cannot be justified by gas phase 478 reactions only. ${ }^{54}$ Future work is needed to assess the importance of DOS photodegradation in the 479 ocean surface and in the atmosphere. ASSOCIATED CONTENT

\section{Supporting information}

483 Material suppliers and water collection procedures; details of solid phase extraction procedures; 484 description of the control experiments; actinometry calculations and theoretical derivation of $485 \Phi_{\text {sulfate}} ;$ lamp spectra; supplementary figures on sulfate production kinetics from natural waters 486 and DOS model compounds; molecular structures of DOS model compounds; literature 487 overview of DOS speciation data from XANES analysis; preliminary results on the 488 photochemical degradation of sulfite to sulfate; numerical values of initial total sulfur, DOC, 
489 sulfate, $\mathrm{pH}, \mathrm{SUVA}_{254}$ of the natural water samples; numerical values of initial rates of sulfate 490 production, initial sulfate production quantum yields, photoproducts distributions; overview of 491 environmental occurrence of DOS model compounds.

\section{Abbreviations}

493 COS, carbonyl sulfide; $\mathrm{CS}_{2}$, carbon disulfide; DMS, dimethylsulfide; DMSO, dimethylsulfoxide; 494 DOC, dissolved organic carbon; DOM, dissolved organic matter; DOS, dissolved organic sulfur; 495 DS, Dismal Swamp; HRMS, high-resolution mass spectrometry; MSA, methanesulfonic acid; 496 MSIA; methanesulfinic acid; PLFA, Pony Lake fulvic acid; PPRI, photochemically produced 497 reactive intermediate.

498 AUTHOR INFORMATION

499 Corresponding Authors

$500 \quad$ * kris.mcneill@env.ethz.ch

\section{$501 \quad$ Author Contributions}

502 R.O., P.R.E., J.T., L.H.E.W. and K.M. designed the experiments. R.O. and B.C. performed the 503 irradiation experiments, the IC and UPLC analyses. J.T. performed the ICP-MS/MS and the 504 HPLC-ICP-MS/MS analyses. R.O. analyzed the data and wrote the manuscript with 505 contributions from P.R.E., J.T., L.H.E.W. and K.M..

\section{Funding sources}

507 The authors acknowledge ETH Zurich for funding.

\section{Acknowledgements}


The authors thank Dr. N. Borduas-Dedekind for the fruitful discussions on the atmospheric chemistry implications of the study. We acknowledge Prof. Dr. M. H. Schroth and B. Studer for the instrumental support on the ion chromatography analyses, and Dr. G. Getzinger for the optimization of the solid phase extraction procedures of the Prairie Pothole samples. We thank Prof. Dr. K. Mopper for the collection of Dismal Swamp water (2014), Dr. V. S. Lin also for the collection of Dismal Swamp water (2016), Dr. C. Chu, C. A. Davis, Dr. E. Janssen and M. Schmitt for the collection of water from Étang de la Gruère, Dr. M. Sander, N. Walpen, Dr. G. Getzinger and Prof. Dr. M. H. Schroth for the collection of the Storhultsmossen pool water samples, and Prof. Dr. W. Arnold and his group for having provided the surface and porewater samples from the Prairie Pothole wetlands.

\section{References}

(1) Mopper, K.; Kieber, D. J.; Stubbins, A. Chapter 8 - Marine Photochemistry of Organic Matter: Processes and Impacts A2 - Hansell, Dennis A. In Biogeochemistry of Marine Dissolved Organic Matter (Second Edition); Carlson, C. A., Ed.; Academic Press: Boston, 2015; pp 389-450.

(2) Sulzberger, B.; Austin, A. T.; Cory, R. M.; Zepp, R. G.; Paul, N. D. Solar UV Radiation in a Changing World: Roles of Cryosphere-Land-Water-Atmosphere Interfaces in Global Biogeochemical Cycles. Photochem. Photobiol. Sci. 2019, 18 (3), 747-774. https://doi.org/10.1039/C8PP90063A.

(3) Cory, R. M.; Ward, C. P.; Crump, B. C.; Kling, G. W. Sunlight Controls Water Column Processing of Carbon in Arctic Fresh Waters. Science 2014, 345 (6199), 925-928. https://doi.org/10.1126/science.1253119.

(4) Adair, E. C.; Parton, W. J.; King, J. Y.; Brandt, L. A.; Lin, Y. Accounting for Photodegradation Dramatically Improves Prediction of Carbon Losses in Dryland Systems. Ecosphere 2017, 8 (7), e01892. https://doi.org/10.1002/ecs2.1892.

(5) Moran, M. A.; Zepp, R. G. Role of Photoreactions in the Formation of Biologically Labile Compounds from Dissolved Organic Matter. Limnol. Oceanogr. 1997, 42 (6), 1307-1316. https://doi.org/10.4319/lo.1997.42.6.1307.

(6) Bushaw, K. L.; Zepp, R. G.; Tarr, M. A.; Schulz-Jander, D.; Bourbonniere, R. A.; Hodson, R. E.; Miller, W. L.; Bronk, D. A.; Moran, M. A. Photochemical Release of Biologically Available Nitrogen from Aquatic Dissolved Organic Matter. Nature 1996, 381 (6581), 404-407. https://doi.org/10.1038/381404a0. 
(7) Vähätalo, A. V.; Zepp, R. G. Photochemical Mineralization of Dissolved Organic Nitrogen to Ammonium in the Baltic Sea. Environ. Sci. Technol. 2005, 39 (18), 6985-6992. https://doi.org/10.1021/es050142z.

(8) Gardolinski, P. C. F. C.; Worsfold, P. J.; McKelvie, I. D. Seawater Induced Release and Transformation of Organic and Inorganic Phosphorus from River Sediments. Water Res. 2004, 38 (3), 688-692. https://doi.org/10.1016/j.watres.2003.10.048.

(9) Du, Q.; Mu, Y.; Zhang, C.; Liu, J.; Zhang, Y.; Liu, C. Photochemical Production of Carbonyl Sulfide, Carbon Disulfide and Dimethyl Sulfide in a Lake Water. J. Environ. Sci. 2017, 51 (Supplement C), 146-156. https://doi.org/10.1016/j.jes.2016.08.006.

(10) Uher, G.; Pillans, J. J.; Hatton, A. D.; Upstill-Goddard, R. C. Photochemical Oxidation of Dimethylsulphide to Dimethylsulphoxide in Estuarine and Coastal Waters. Chemosphere 2017, 186 (Supplement C), 805-816. https://doi.org/10.1016/j.chemosphere.2017.08.050.

(11) Gomez-Saez, G. V.; Pohlabeln, A. M.; Stubbins, A.; Marsay, C. M.; Dittmar, T. Photochemical Alteration of Dissolved Organic Sulfur from Sulfidic Porewater. Environ. Sci. Technol. 2017, 51 (24), 14144-14154. https://doi.org/10.1021/acs.est.7b03713.

(12) Stubbins, A.; Dittmar, T. Illuminating the Deep: Molecular Signatures of Photochemical Alteration of Dissolved Organic Matter from North Atlantic Deep Water. Mar. Chem. 2015, 177 (2), 318-324. https://doi.org/10.1016/j.marchem.2015.06.020.

(13) Antony, R.; Willoughby, A. S.; Grannas, A. M.; Catanzano, V.; Sleighter, R. L.; Thamban, M.; Hatcher, P. G. Photo-Biochemical Transformation of Dissolved Organic Matter on the Surface of the Coastal East Antarctic Ice Sheet. Biogeochemistry 2018, 141 (2), 229-247. https://doi.org/10.1007/s10533-018-0516-0.

(14) Herzsprung, P.; Hertkorn, N.; Friese, K.; Schmitt-Kopplin, P. Photochemical Degradation of Natural Organic Sulfur Compounds (CHOS) from Iron-Rich Mine Pit Lake Pore Waters--an Initial Understanding from Evaluation of Single-Elemental Formulae Using Ultra-High-Resolution Mass Spectrometry. Rapid Commun. Mass Spectrom. RCM 2010, 24 (19), 2909-2924. https://doi.org/10.1002/rcm.4719.

(15) Hoffmann, E. H.; Tilgner, A.; Schrödner, R.; Bräuer, P.; Wolke, R.; Herrmann, H. An Advanced Modeling Study on the Impacts and Atmospheric Implications of Multiphase Dimethyl Sulfide Chemistry. Proc. Natl. Acad. Sci. 2016, 113 (42), 11776-11781. https://doi.org/10.1073/pnas.1606320113.

(16) King, G. M.; Klug, M. J. Sulfhydrolase Activity in Sediments of Wintergreen Lake, Kalamazoo County, Michigan. Appl. Environ. Microbiol. 1980, 39 (5), 950-956.

(17) Laszakovits, J. R.; Berg, S. M.; Anderson, B. G.; O’Brien, J. E.; Wammer, K. H.; Sharpless, C. M. P-Nitroanisole/Pyridine and p-Nitroacetophenone/Pyridine Actinometers Revisited: Quantum Yield in Comparison to Ferrioxalate. Environ. Sci. Technol. Lett. 2016, 4, 1114. https://doi.org/10.1021/acs.estlett.6b00422.

(18) Ksionzek, K. B.; Lechtenfeld, O. J.; McCallister, S. L.; Schmitt-Kopplin, P.; Geuer, J. K.; Geibert, W.; Koch, B. P. Dissolved Organic Sulfur in the Ocean: Biogeochemistry of a Petagram Inventory. Science 2016, 354 (6311), 456-459.

https://doi.org/10.1126/science.aaf7796.

(19) Cutter, G. A.; Cutter, L. S.; Filippino, K. C. Sources and Cycling of Carbonyl Sulfide in the Sargasso Sea. Limnol. Oceanogr. 2004, 49 (2), 555-565. https://doi.org/10.4319/1o.2004.49.2.0555.

(20) Fimmen, R. L.; Cory, R. M.; Chin, Y.-P.; Trouts, T. D.; McKnight, D. M. Probing the Oxidation-Reduction Properties of Terrestrially and Microbially Derived Dissolved 
Organic Matter. Geochim. Cosmochim. Acta 2007, 71 (12), 3003-3015. https://doi.org/10.1016/j.gca.2007.04.009.

(21) Liu, Z.-Q.; Shah, A. D.; Salhi, E.; Bolotin, J.; von Gunten, U. Formation of Brominated Trihalomethanes during Chlorination or Ozonation of Natural Organic Matter Extracts and Model Compounds in Saline Water. Water Res. 2018, 143, 492-502. https://doi.org/10.1016/j.watres.2018.06.042.

(22) Sleighter, R. L.; Chin, Y.-P.; Arnold, W. A.; Hatcher, P. G.; McCabe, A. J.; McAdams, B. C.; Wallace, G. C. Evidence of Incorporation of Abiotic S and N into Prairie Wetland Dissolved Organic Matter. Environ. Sci. Technol. Lett. 2014, 1 (9), 345-350. https://doi.org/10.1021/ez500229b.

(23) Poulin, B. A.; Ryan, J. N.; Nagy, K. L.; Stubbins, A.; Dittmar, T.; Orem, W.; Krabbenhoft, D. P.; Aiken, G. R. Spatial Dependence of Reduced Sulfur in Everglades Dissolved Organic Matter Controlled by Sulfate Enrichment. Environ. Sci. Technol. 2017, 51 (7), 3630-3639. https://doi.org/10.1021/acs.est.6b04142.

(24) Minor, E. C.; Pothen, J.; Dalzell, B. J.; Abdulla, H.; Mopper, K. Effects of Salinity Changes on the Photodegradation and Ultraviolet-Visible Absorbance of Terrestrial Dissolved Organic Matter. Limnol. Oceanogr. 2006, 51 (5), 2181-2186. https://doi.org/10.4319/1o.2006.51.5.2181.

(25) Erickson, P. R.; Moor, K. J.; Werner, J. J.; Latch, D. E.; Arnold, W. A.; McNeill, K. Singlet Oxygen Phosphorescence as a Probe for Triplet-State Dissolved Organic Matter

Reactivity. Environ. Sci. Technol. 2018, 52 (16), 9170-9178. https://doi.org/10.1021/acs.est.8b02379.

(26) Sharpless, C. M.; Aeschbacher, M.; Page, S. E.; Wenk, J.; Sander, M.; McNeill, K. Photooxidation-Induced Changes in Optical, Electrochemical, and Photochemical Properties of Humic Substances. Environ. Sci. Technol. 2014, 48 (5), 2688-2696. https://doi.org/10.1021/es403925g.

(27) Bandstra, J. Z.; Tratnyek, P. G. Central Limit Theorem for Chemical Kinetics in Complex Systems. J. Math. Chem. 2005, 37 (4), 409-422. https://doi.org/10.1007/s10910-0041107-y.

(28) Mostovaya, A.; Hawkes, J. A.; Koehler, B.; Dittmar, T.; Tranvik, L. J. Emergence of the Reactivity Continuum of Organic Matter from Kinetics of a Multitude of Individual Molecular Constituents. Environ. Sci. Technol. 2017, 51 (20), 11571-11579. https://doi.org/10.1021/acs.est.7b02876.

(29) Ulshöfer, V. S.; Flock, O. R.; Uher, G.; Andreae, M. O. Photochemical Production and AirSea Exchange of Carbonyl Sulfide in the Eastern Mediterranean Sea. Mar. Chem. 1996, 53 (1), 25-39. https://doi.org/10.1016/0304-4203(96)00010-2.

(30) Weiss, P. S.; Andrews, S. S.; Johnson, J. E.; Zafiriou, O. C. Photoproduction of Carbonyl Sulfide in South Pacific Ocean Waters as a Function of Irradiation Wavelength. Geophys. Res. Lett. 1995, 22 (3), 215-218. https://doi.org/10.1029/94GL03000.

(31) Flöck, O. R.; Andreae, M. O. Photochemical and Non-Photochemical Formation and Destruction of Carbonyl Sulfide and Methyl Mercaptan in Ocean Waters. Mar. Chem. 1996, 54 (1), 11-26. https://doi.org/10.1016/0304-4203(96)00027-8.

(32) Xie, H.; Moore, R. M. Carbon Disulfide in the North Atlantic and Pacific Oceans. $J$. Geophys. Res. Oceans 1999, 104 (C3), 5393-5402.

https://doi.org/10.1029/1998JC900074. 
(33) Uher, G.; Andreae, M. Photochemical Production of Carbonyl Sulfide in North Sea Water: A Process Study. Limnol. Oceanogr. 2003, 42 (3), 432-442. https://doi.org/10.4319/lo.1997.42.3.0432.

(34) Pos, W. H.; Riemer, D. D.; Zika, R. G. Carbonyl Sulfide (OCS) and Carbon Monoxide (CO) in Natural Waters: Evidence of a Coupled Production Pathway. Mar. Chem. 1998, 62 (1), 89-101. https://doi.org/10.1016/S0304-4203(98)00025-5.

(35) Andreae, M. O.; Ferek, R. J. Photochemical Production of Carbonyl Sulphide in Marine Surface Waters. Nature 1984, 307 (5947), 148. https://doi.org/10.1038/307148a0.

(36) Zepp, R. G.; Andreae, M. O. Factors Affecting the Photochemical Production of Carbonyl Sulfide in Seawater. Geophys. Res. Lett. 1994, 21 (25), 2813-2816. https://doi.org/10.1029/94GL03083.

(37) Modiri Gharehveran, M.; Shah, A. D. Indirect Photochemical Formation of Carbonyl Sulfide and Carbon Disulfide in Natural Waters: Role of Organic Sulfur Precursors, Water Quality Constituents, and Temperature. Environ. Sci. Technol. 2018, 52 (16), 9108-9117. https://doi.org/10.1021/acs.est.8b01618.

(38) Flöck, O. R.; Andreae, M. O.; Dräger, M. Environmentally Relevant Precursors of Carbonyl Sulfide in Aquatic Systems. Mar. Chem. 1997, 59 (1), 71-85. https://doi.org/10.1016/S0304-4203(97)00012-1.

(39) Powers, L. C.; Miller, W. L. Photochemical Production of CO and CO2 in the Northern Gulf of Mexico: Estimates and Challenges for Quantifying the Impact of Photochemistry on Carbon Cycles. Mar. Chem. 2015, 171, 21-35. https://doi.org/10.1016/j.marchem.2015.02.004.

(40) Kelly, D. P.; Smith, N. A. Organic Sulfur Compounds in the Environment Biogeochemistry, Microbiology, and Ecological Aspects. In Advances in Microbial Ecology; Springer, Boston, MA, 1990; pp 345-385. https://doi.org/10.1007/978-1-46847612-5_9.

(41) Hu, H.; Mylon, S. E.; Benoit, G. Distribution of the Thiols Glutathione and 3Mercaptopropionic Acid in Connecticut Lakes. Limnol. Oceanogr. 2006, 51 (6), 27632774. https://doi.org/10.4319/lo.2006.51.6.2763.

(42) Dupont, C. L.; Moffett, James. W.; Bidigare, R. R.; Ahner, B. A. Distributions of Dissolved and Particulate Biogenic Thiols in the Subartic Pacific Ocean. Deep Sea Res. Part Oceanogr. Res. Pap. 2006, 53 (12), 1961-1974. https://doi.org/10.1016/j.dsr.2006.09.003.

(43) Tang, D.; Hung, C.-C.; Warnken, K. W.; Santschi, P. H. The Distribution of Biogenic Thiols in Surface Waters of Galveston Bay. Limnol. Oceanogr. 2000, 45 (6), 1289-1297. https://doi.org/10.4319/lo.2000.45.6.1289.

(44) Cory, R. M.; Kling, G. W. Interactions between Sunlight and Microorganisms Influence Dissolved Organic Matter Degradation along the Aquatic Continuum. Limnol. Oceanogr. Lett. 2018, 3, 102-116. https://doi.org/10.1002/lol2.10060.

(45) Baker, S. C.; Kelly, D. P.; Murrell, J. C. Microbial Degradation of Methanesulphonic Acid: A Missing Link in the Biogeochemical Sulphur Cycle. Nature 1991, 350 (6319), 627-628. https://doi.org/10.1038/350627a0.

(46) Kelly, D. P.; Murrell, J. C. Microbial Metabolism of Methanesulfonic Acid. Arch. Microbiol. 1999, 172 (6), 341-348. https://doi.org/10.1007/s002030050770.

(47) Henriques, A. C.; Marco, P. D. Methanesulfonate (MSA) Catabolic Genes from Marine and Estuarine Bacteria. PLOS ONE 2015, 10 (5), e0125735. https://doi.org/10.1371/journal.pone.0125735. 
(48) McNeill, V. F. Aqueous Organic Chemistry in the Atmosphere: Sources and Chemical Processing of Organic Aerosols. Environ. Sci. Technol. 2015, 49 (3), 1237-1244. https://doi.org/10.1021/es5043707.

(49) Quinn, P. K.; Collins, D. B.; Grassian, V. H.; Prather, K. A.; Bates, T. S. Chemistry and Related Properties of Freshly Emitted Sea Spray Aerosol. Chem. Rev. 2015, 115 (10), 4383-4399. https://doi.org/10.1021/cr500713g.

(50) Quinn, P. K.; Bates, T. S. The Case against Climate Regulation via Oceanic Phytoplankton Sulphur Emissions. Nature 2011, 480 (7375), 51-56. https://doi.org/10.1038/nature10580.

(51) Quinn, P. K.; Coffman, D. J.; Johnson, J. E.; Upchurch, L. M.; Bates, T. S. Small Fraction of Marine Cloud Condensation Nuclei Made up of Sea Spray Aerosol. Nat. Geosci. 2017, 10 (9), 674-679. https://doi.org/10.1038/ngeo3003.

(52) Cheng, Y.; Zheng, G.; Wei, C.; Mu, Q.; Zheng, B.; Wang, Z.; Gao, M.; Zhang, Q.; He, K.; Carmichael, G.; Pösch1, U.; Su, H. Reactive Nitrogen Chemistry in Aerosol Water as a Source of Sulfate during Haze Events in China. Sci. Adv. 2016, 2 (12), e1601530. https://doi.org/10.1126/sciadv.1601530.

(53) Gen, M.; Zhang, R.; Huang, D. D.; Li, Y.; Chan, C. K. Heterogeneous Oxidation of SO2 in Sulfate Production during Nitrate Photolysis at 300 Nm: Effect of PH, Relative Humidity, Irradiation Intensity, and the Presence of Organic Compounds. Environ. Sci. Technol. 2019, 53 (15), 8757-8766. https://doi.org/10.1021/acs.est.9b01623.

(54) Zheng, B.; Zhang, Q.; Zhang, Y.; He, K. B.; Wang, K.; Zheng, G. J.; Duan, F. K.; Ma, Y. L.; Kimoto, T. Heterogeneous Chemistry: A Mechanism Missing in Current Models to Explain Secondary Inorganic Aerosol Formation during the January 2013 Haze Episode in North China. Atmospheric Chem. Phys. 2015, 15 (4), 2031-2049. https://doi.org/10.5194/acp-15-2031-2015. 
B

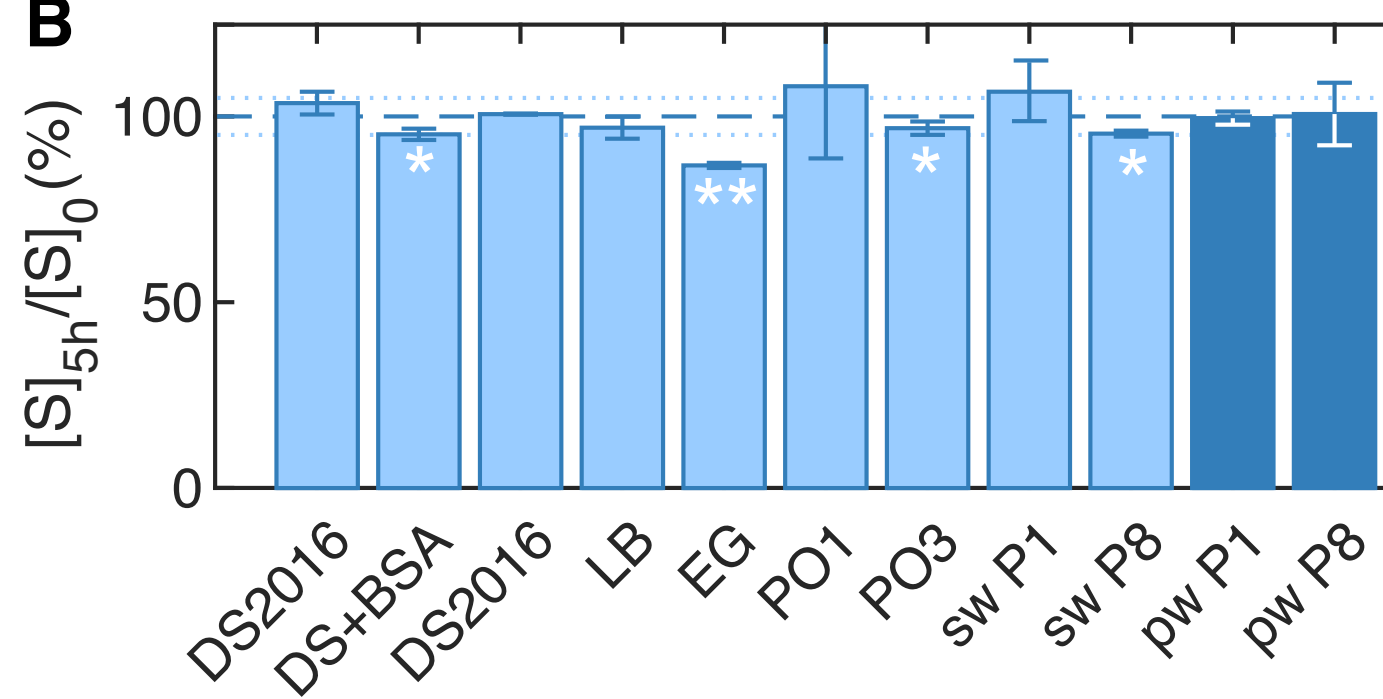

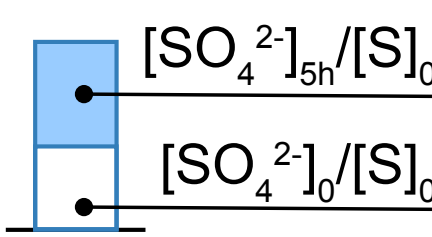

aquatic, surface water DOM aquatic, porewater DOM soil DOM 
DOS aerosol

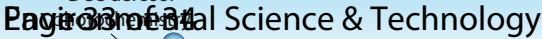
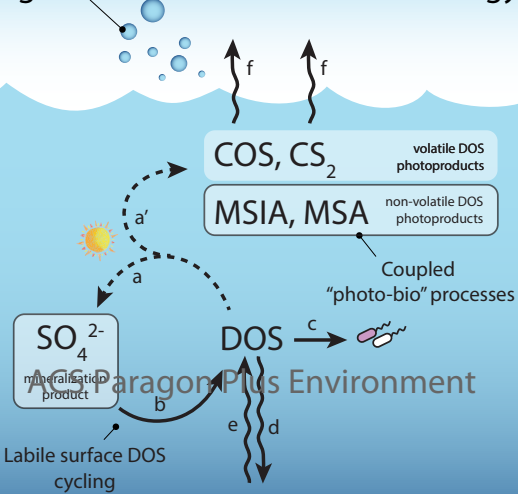


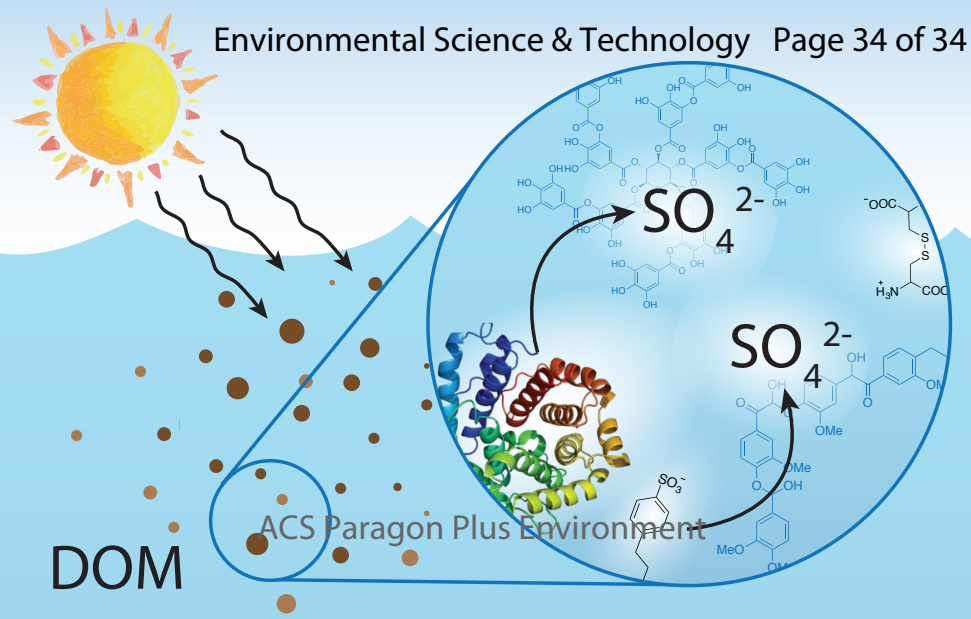

